\title{
A FUNDAÇÃO DOS CURSOS JURÍDICOS NO BRASIL
}

\author{
Antonio Augusto Machado de Campo Neto \\ Chefe do Serviço Técnico de Imprensa da Faculdade \\ de Direito da Universidade de São Paulo \\ Andrey Borges de Mendonça’ \\ Aluno do Curso de Graduação da Faculdade de \\ Direito da Universidade de São Paulo
}

Resumo:

Os autores abordam as tentativas de criação dos cursos juridicos no País, as discrepâncias dos parlamentares com relação a qual cidade seria a sede da nossa primeira Universidade, realizando um apanhado sobre 0 contexto histórico presente àquela época e finalizando com a Lei de 11 de agosto de 1827 .

\begin{abstract}
:
The author's study is about the attempts of creation of the juridical courses in the Country, the parliamentarians' discrepancies about which city would be the headquarters of our first University, accomplishing a summary of the present historical context about that time and concluding with the Law of August 11, 1827.
\end{abstract}

Unitermos: primeira e segunda tentativas da fundação dos cursos jurídicos; Lei n. de 11 de agosto de 1827

Em 1624 a Vila de São Paulo já era um dos maiores expoentes dentre as pequenas vilas do País, sendo hoje a capital mais dinâmica, com ênfase à economia e à cultura em geral. Em 28 de novembro de 1624 o rei Felipe III, de Portugal, concedeu o alvará de autorização para a fundação de conventos franciscanos em São Paulo e na Bahia, além de outras localidades do Brasil. Naquele ano, em 29 de novembro, foi criado o Convento de São Francisco que, em 1824, veio acolher a Academia de Direito. O convento já pertencia à Ordem Seráfica de São Francisco de Assis, sendo frei Henrique de Coimbra, que viera com a frota de Pedro Álvares Cabral, o primeiro religioso a representá-la em terras brasileiras. O 
destino da Ordem foi concretizado, em 1639, graças à intervenção dos franciscanos, liderados por frei Manuel de Santa Maria que, naquele ano, veio a São Paulo com a finalidade de escolher o local, respaldado pelos moradores da Vila, e implantá-la. De início na atual Rua Direita, no ano de 1640, todavia três anos depois, vindo à Vila de São Paulo, o custódio frei Francisco das Neves considerou o local inconveniente e sob suas ordens a transferência do Convento foi realizada para o Largo de São Francisco.

As obras do Convento, entretanto, ficaram paralisadas até 1644, tendo a partir deste ano sua progressividade na edificação, que tem como perfil a atual igreja, localizada ao lado da Academia.

E a Academia teve sua criação proposta pela primeira vez à Assembléia Constituinte por José Feliciano Fernandes Pinheiro, posteriormente Visconde de São Leopoldo, em sessão de 14 de junho de 1823.

O propósito de Fernandes Pinheiro era ressaltar o quanto os estudantes brasileiros eram ridicularizados, naquela época, em Coimbra. Época em que Portugal não havia ainda se acostumado em considerar o Brasil como independente.

E através do Capítulo VI do Regimento Interno da Assembléia Constituinte de São Paulo propunha que "no Império do Brasil se crie, quanto antes, uma Universidade, pelo menos, para assunto do qual parece dever ser preferida a Cidade de São Paulo, pelas vantagens naturais, e razões de conveniência geral. Que na Faculdade de Direito Cível, que será sem dúvida uma das que comporá (sic) a nova Universidade, em vez de multiplicadas Cadeiras de Direito Romano, se substituam duas, uma de Direito Público Constitucional, outra de Economia Política. Paço da Assembléia, 12 de junho de 1823. Deputado José Feliciano Fernandes Pinheiro"

Após a indicação, sendo que o proponente havia solicitado prioridade à Assembléia, decidiu-se remetê-la à Comissão de Instrução Pública para que fosse transformada em projeto de lei.

Sendo assim, em sessão de 19 de agosto de 1823 o deputado Ribeiro de Andrada em nome da Comissão de Instrução Pública relatou:

"A Assembléia Geral Constituinte e Legislativa do Brasil decreta:

$1^{\circ}$ Haverão (sic) duas universidades, uma na cidade de S. Paulo, e outra na de Olinda, nas quais se ensinarão todas as ciências e belas-letras.

$2^{o}$ Estatutos próprios regularão o número e ordenado dos professores, a ordem e arranjamento dos estudos. 
$3^{\circ} \mathrm{Em}$ tempo competente, se designarão os fundos precisos a ambos os estabelecimentos.

$4^{\circ}$ Entretanto, haverá, desde já, um curso jurídico na cidade de $S$. Paulo, para o qual o Governo convocará mestres idôneos, os quais se governarão, provisoriamente, pelos estatutos da Universidade de Coimbra, com aquelas alterações e mudanças, que eles, em mesa presidida pelo Vice-Reitor, julgarem adequadas às circunstâncias e luzes do século.

$5^{\circ}$ Sua Majestade o Imperador escolherá, dentre os mestres, um para servir interinamente de Vice-Reitor. Paço da Assembléia, 19 de agosto de 1823. Martim Francisco Ribeiro de Andrada, Antônio Rodrigues Veloso de Oliveira, Belchior Pinheiro de Oliveira, Antônio Gonçalves Gomide, Manuel Jacinto Nogueira da Gama.

O projeto foi então impresso para debate.

Na primeira discussão, em 27 de agosto de 1823, iniciaram as divergências, como, por exemplo, o parecer verbal do deputado Almeida e Albuquerque que considerava "prematura a criação de universidades, e não haver fundos para tão grande empreendimento"

Albuquerque preferia a escolha da Capital do Império para a sede dos cursos jurídicos, alegando que "nenhuma parte pode a Ciência do Direito ensinar-se já com mais facilidade do que aqui na Corte, onde a concorrência de maior número de jurisconsultos habilita a abertura do curso jurídico desde já; o que não acontecerá assim em outra qualquer Província. Não digo que fique sendo na Corte que ensinem para o futuro as faculdades jurídicas; nem sou da opinião que a universidade se estabeleça aqui; mas sustento que só aqui é que pode abrir-se, desde já, um curso jurídico e não em outra alguma parte"

Alguns se contrapunham como o deputado Fernandes Pinheiro, de São Paulo, outros concordavam como o deputado Montezuma, da Bahia.

Este último asseverava que se a implantação dos cursos jurídicos fosse em São Paulo seria impossível aos habitantes de Pernambuco, Ceará, Piauí, Maranhão, etc. uma vez São Paulo ficar muito distante em parâmetro como, por exemplo, a Bahia, mais centralizada tanto para o Norte quanto para o Sul do Império.

O deputado Luís José de Carvalho e Mello, depois Visconde da Cachoeira, manifestou-se também pela criação da universidade em São Paulo e compendiou as razões que mais tarde prevaleceram nas seguintes argumentações: 
a cidade de $S$. Paulo é muito próxima ao porto de Santos, tem baratos víveres, tem clima saudável e moderado, e é muito abastecida de gêneros de primeira necessidade, e os habitantes das Províncias do Sul, e do interior de Minas, podem ali dirigir os seus jovens filhos com comodidade. $O$ estabelecimento da outra em Olinda apresenta semelhantes circunstâncias, e é a situação apropriada para ali virem os estudantes das Províncias do Norte.

Com muita justiça, e utilidade, se estabelece a criação de duas universidades, porque, em tamanha extensão de território, que temos a fortuna de possuir, era impraticável que pudesse bastar só uma, como acontece em Portugal, que, tendo tão limitada extensão, a única de Coimbra, onde fomos beber os princípios que desenvolvemos depois, era, e é, bastante para os habitantes de todo aquele acanhado reino. Porventura, se consideramos a extensão do comprimento, $e$ largura, deste Império, dir-se-á que são poucas as mesmas duas que se pretendem estabelecer.

$E$ isto verdade, considerada a questão neste ponto de vista: mas lembrando-nos da falta de povoação, que ainda temos, e que nos faltará por muito tempo, dos poucos meios para sustentação de estabelecimentos tão dispendiosos, $e$ sobretudo da falta de mestres, devemos, por ora, contentarmo-nos com as duas, deixando ao tempo, e às futuras circunstâncias, o criarem-se algumas mais, suprimindo, entretanto, os colégios científicos que, com o andar do tempo, se erguerão em diversas Províncias"

Assim o andamento do Projeto foi debatido em primeira discussão nas sessões de 27 e 28 de agosto de 1823; em segunda discussão nas sessões de 05 e 06 de setembro e em 06 de outubro de 1823; e em terceira nas sessões de 18 e 27 de outubro, sendo sancionado a 04 de novembro, como lei, pela Assembléia.

Todavia o Poder Executivo não promulgou nem publicou este Ato assim como vários outros Alos sancionados pela Assembléia Constituinte. E a 12 de novembro de 1823 a Assembléia é dissolvida por D. Pedro I.

Uma luta interna provocou grande comoção social envolvendo os Andradas, que possuíam a propriedade do tablóide $A$ Sentinela que publicara artigos contra os oficiais portugueses da Guarnição, o deputado Antonio Carlos, que instiga a Assembléia a se declarar em sessão permanente durante os dias 11 e 12 de novembro daquele ano, e o imperador, que já sentia a hostilidade da Assembléia, culminando por levar os antigos soldados portugueses às fileiras do Exército. A 
Assembléia solicita a presença do ministro do Império, Marquês de Paranaguá, para a solução do caso.

E chega-se ao ápice da questão, quando a Assembléia reivindica a presença do ministro da Guerra.

Ansiava-se naquela época a liberdade de imprensa, uma vez ter havido desentendimento entre o farmacêutico Davi Pamplona Corte Real, autor do artigo Um Brasileiro Resoluto, publicado no $A$ Sentinela, no qual critica os oficiais portugueses da Guarnição, e o major Lapa e o capitão Pimentel, que chegaram a agredir o farmacêutico do Largo da Carioca.

Manifestações populares se iniciaram, muitos invadem o recinto das sessões exigindo a punição dos culpados.

O imperador vem à frente da Cavalaria, faz-se cercar o Paço da Câmara por força militar e manda que o brigadeiro Morais entregue ao presidente do Senado o Decreto de 12 de novembro, que declara dissolvida a Assembléia Constituinte.

Naquele golpe de Estado a primeira tentativa da fundação dos cursos jurídicos chega a sucumbir.

$\mathrm{Na}$ segunda tentativa, a retomada é iniciada pelo deputado mineiro Lúcio Soares Teixeira de Gouveia, em 12 de maio de 1826, propondo à então Comissão de Instrução Pública a revisão dos trabalhos da Assembléia Constituinte que havia sancionado o Projeto de lei sobre a criação dos cursos jurídicos no País, cujo mérito era respaldado na expressão objeto de muita urgência, porque da instrução da nossa mocidade dependia, em grande parte, a consolidação do sistema constitucional' E em 17 de maio, na sessão sucessora, vêm à tona, novamente, os locais de preferência para a instalação dos cursos jurídicos, ou mais precisamente, da universidade. Em 05 de julho de 1826, o presidente da Comissão, Januário da Cunha Barbosa, apresenta o Projeto de Lei, a seguir transcrito, que teve como coordenador o deputado José Cardoso Pereira de Melo:

"A Assembléia Legislativa decreta:

Art. 1. Estabelecer-se-á um curso jurídico, ou de ciências sociais, por agora no Rio de Janeiro, o qual constará de oito cadeiras, distribuídas e ordenadas da maneira seguinte:

\section{$1^{3}$ - Direito Natural e Direito das Gentes. \\ $2^{a}$ - Direito Pátrio Civil e Criminal. \\ História da Legislação Nacional.}


$3^{a}$ - Filosofia Jurídica, ou Principios Gerais de Legislação. História das Legislações Antigas e seus Efeitos Politicos.

$4^{a}$ - Instituições Canônicas e História Eclesiástica.

$5^{a}$ - Direito Público, Estatística Universal.

Geografia Política.

$6^{a}$ Direito Político, ou Análise das Constituições dos Diversos Governos Antigos e Modernos.

$7^{\text {a }}$ - Economia Política.

$8^{a}$ - História Filosófica e Política das Nações, ou Discussão Histórica dos seus Interesses Recíprocos e suas Negociações.

Art. 2. Para regência destas cadeiras, o Governo nomeará oito lentes, e quatro substitutos, os quais, desde já organizarão, congregados, um regulamento sobre as horas em que devem explicar as diferentes matérias, de forma que todo o curso não exceda de quatro anos e que as tardes sejam livres.

Art. 3. Os estatutos da Universidade de Coimbra, relativamente aos seus reitores, servirão aqui provisoriamente na sua parte aplicável.

Art. 4. Cada um dos lentes vencerá o honorário anual de $800 \$ 000$, e cada um dos substitutos o de $400 \$ 000$.

Art. 5. Haverá um secretário, com o ordenado de 600\$000, um porteiro com $400 \$ 000$, e seus serventuários, que se julgarem indispensáveis e como ordenado que parecer justo.

Art. 6. Cada um dos lentes fará escolha do compêndio da sua profissão, ou o arranjará, não existindo já feito, e exporá à aprovação dos lentes congregados; esta o remeterá ao Governo para fazer imprimir, e fornecer às escolas, dando ao seu autor a terça parte do lucro, calculada pela venda da primeira edição.

Art. 7. Os estudantes, que se quiserem matricular no primeiro ano do Curso Jurídico, devem apresentar certidão de idade, e de aprovação em gramática latina, retórica, filosofia racional e moral; estes exames serão feitos por três professores públicos, presididos pelo decano dos lentes.

Art. 8. Nenhum estudante se poderá matricular sem ter quinze anos completos, nenhum será admitido à matrícula do segundo ano, sem apresentar certidão de aprovação de geometria em alguma das Academias.

Art. 9. Os estudantes, assim habilitados, farão petição aos lentes do respectivo ano para os admitir à matrícula, que será gratuita. 
Art. 10. As matrículas principiarão no dia quinze de fevereiro, e se fecharão no último do dito mês.

Art. 11. O tempo letivo começará no primeiro de março e terminará a 15 de novembro, abrindo-se as aulas de verão às oito horas, e de inverno às nove.

Art. 12. No dia 15 de novembro todos os lentes se congregarão, para julgarem a habilitação dos estudantes, que houverem freqüentado as aulas, e que devem, em conseqüência disto, ser admitidos a exame.

Art. 13. No dia 15 de novembro, começarão os atos, e acabarão no dia 20 de dezembro, em que se fecharão as aulas.

Art. 14. A congregação dos lentes formará e apresentará à aprovação do Governo os estatutos necessários que devem regular as matrículas, os exames, os graus, o modo de passar as cartas, o selo, e tudo mais que for relativo à economia das aulas.

Art. 15. A direção e inspeção imediata destes estudos pertence ao Ministro e Secretário de Estado dos Negócios do Império.

Art. 16. A execução desta lei deve ter princípio quanto antes, para que possa começar o Curso Jurídico em março do ano de 1827. Paço da Câmara dos Deputados, em 5 de julho de 1826. Januário da Cunha Barbosa. José Cardoso Pereira de Melo"

Em 05 de julho foi impresso o Projeto, entrando em pauta em $1^{\circ}$ de agosto de 1826 , sendo aprovado.

Uma série de emendas vai se acumulando, sendo a primeira na sessão de 05 de agosto de 1826, oferecida pelo deputado Teixeira de Gouveia, para que o curso jurídico fosse definitivamente estabelecido em São Paulo.

Numa das emendas, de autoria de José Clemente Pereira, o curso jurídico seria composto de dez cadeiras, distribuídas e ordenadas da seguinte maneira:

$1^{\circ}$ Ano:

$1^{\text {a }}$ Direito Natural.

$2^{\mathbf{a}}$ - Instituições de Direito Romano.

$2^{\circ}$ Ano:

$1^{\mathrm{a}}$ - Direito Público Universal e das Gentes.

$2^{\mathrm{a}}$ - Direito Público Eclesiástico.

$3^{\circ}$ - Ano:

$1^{\mathrm{a}}$ Direito Pátrio, Público e Civil. 
$2^{\mathrm{a}}$ - Direito Pátrio Criminal e do Comércio.

$4^{\circ}$ Ano:

$1^{\mathrm{a}}$ - Direito Pátrio Civil.

$2^{\mathrm{a}}$ Economia Política.

$5^{\circ}$ Ano:

$1^{a}$ Prática.

$2^{\mathrm{a}}$ Estatística, Geografia Política e Diplomacia.

Acrescentava Clemente Pereira que os lentes, que no primeiro ano ocupassem a cadeira de Direito Natural, passariam a ocupar, no segundo, a de Direito Público Universal e das Gentes, praticando-se o mesmo nas cadeiras de Direito Civil do terceiro e quarto anos.

O Direito Natural era a primeira cadeira escolhida para ilustrar o conteúdo do curso jurídico, porque era a base filosófica que repassava, através de seus conceitos, o Direito propriamente dito a ser adotado naquele período. Período em que apareceriam as correntes positivistas, lideradas por Emmanuel Kant, pensador que mais influiu na filosofia jurídica, afirmando que a liberdade seria o único direito inato do homem.

Uma das passagens mais importantes e pitorescas, que para nós, estudiosos do Direito, chega a ser hilária é o comentário do deputado mineiro Bernardo Pereira de Vasconcelos de que entre tantas emendas, discussões e pareceres sobre quais as matérias que deveriam constar do curso jurídico com relação à introdução do Direito Romano: " o Direito Romano é o direito da trapaça $e$ o advogado, ou o ministro, que nele se faz forte, é, por via de regra, mau advogado e mau ministro' palavras proferidas em sessão de 08 de agosto de 1826 !

O fato é que a maioria dos membros da Assembléia tomava, por parâmetro, não-só o currículo de Coimbra como também o da França, Alemanha e Inglaterra, expoentes máximos daqueles anos.

E nesses qüiproquós, alguém tem a idéia de propor a criação de dois cursos jurídicos: um em São Paulo e o outro em Olinda; o idealizador foi o deputado paulista Francisco de Paula Sousa e Mello. A proposta veio mais tarde a se prevalecer e é justo considerá-lo como um dos beneméritos fundadores da Academia do Largo de São Francisco.

A idéia da instalação dos cursos jurídicos em conventos das cidades surgiu em 14 de agosto de 1826, de autoria do deputado Paula e Sousa, antecipando, 
desta maneira, o que viria a se suceder na história da instalação dos cursos jurídicos no País.

No âmbito de dezenas de emendas várias redações, propostas, dissertações sobre quais as matérias convenientes que fariam parte do currículo sucede que em 18 de agosto de 1826 é apresentada a nova redação do Projeto, que entra em terceira discussão na sessão do dia 23 de agosto de 1826 . Há divergências entre os deputados, sendo acrescentada outra nova redação em 29 de agosto, em consonância com as emendas apoiadas pela Comissão de Instrução Pública.

Em 31 de agosto, o Projeto entra em última discussão e é terminado o trajeto da história legislativa no âmbito da Câmara dos Deputados que trouxe os seus conhecimentos da época, a boa-vontade dos parlamentares, o anseio da sociedade que se avantajava com glamour e a construção dos alicerces do ensino jurídico no Pais.

No Senado, o Projeto entra em primeira discussão em 18 de maio de 1827. E em 04 de julho de 1827, aprovado sem emendas.

Uma das características do Projeto aprovado é a da remuneração dos lentes que assinalava dever ser a mesma dos desembargadores.

Consta da leitura dos Anais do Senado o esforço dos senadores em aprová-lo de imediato, aprovando-o conforme viera da Câmara dos Deputados.

A lei é promulgada em 11 de agosto de 1827, criando, assim, os cursos jurídicos de São Paulo e de Olinda. Em seu perfil a distribuição em cinco anos com um total de nove cadeiras. No primeiro ano: Direito Natural e Direito Público, compreendendo Análise da Constituição do Império, Direito das Gentes e Diplomacia. No segundo ano a continuação das matérias antecedentes, acrescentando-se Direito Público Eclesiástico. No terceiro ano: Direito Civil Pátrio e Direito Pátrio Criminal. No quarto ano, continuação do Direito Civil Pátrio e Direito Mercantil e Marítimo e, finalmente, no quinto ano Economia Política e Teoria à Prática do Processo.

Narrar em poucas palavras a história da Faculdade de Direito de São Paulo é querer resumir em algumas linhas boa parte da história do País nestes últimos 172 anos, tal a influência que ela exerceu em todos os setores, com ênfase à Política. Desde a fundação dos Cursos Juridicos estão presentes os estudantes nos grandes momentos cívicos, literários e políticos do País. Manifestaram-se pública e ruidosamente contra as violências e arbitrariedades de D. Pedro I; estavam eles em luta quando é assassinado a bacamarte o médico e jornalista italiano Giovanni 
Battista Libero Badaró, diretor do jornal Observador Constitucional que, ao morrer, no seu último alento, eleva a voz altaneiramente, dizendo: "Morre um liberal, mas não morre a liberdade". Estavam presentes nos primeiros jornais de São Paulo, como $O$ Paulistano e $O$ Paulista; assinalavam a poesia romântica com Álvares de Azevedo, Fagundes Varella e Castro Alves; participaram na Guerra do Paraguai, inflamados e inflamando o País pela poesia de Castro Alves ou, ainda, pelos discursos de Rui Barbosa e pela mensagem de José Maria da Silva Paranhos, Barão do Rio Branco, dirigida ao vencedor de Riachuelo.

Lutaram pela Lei do Ventre Livre, pela Abolição e pela República; marcam indelevelmente a presença na política da República pelos colegas Prudente de Morais, Rodrigues Alves, Campos Sales, Afonso Pena, Wenceslau Brás, Arthur Bernardes e Washington Luís. Estavam envolvidos na Revolução de 1930 e derramaram seus sangues na epopéia constitucionalista de 1932.

Nunca cessou a luta dos acadêmicos do Largo de São Francisco, que foram pisados pelos policiais do Estado Novo, tomando parte na recuperação democrática de 1945 e mais recentemente nas Diretas-Já, em 1984.

E assim foram instalados, em 11 de agosto de 1827, os cursos jurídicos em São Paulo e em Olinda. O ministro do Império, Fernandes Pinheiro, apresenta a D. Pedro os nomes do tenente-general José Arouche de Toledo Rendon, paulistano de 71 anos de idade, doutor em leis e em armas, e do professor José Maria de Avelar Brotero, para, respectivamente, diretor e lente do primeiro ano, sendo esses nomes aceitos pelo imperador.

Arouche Rendon imediatamente tratou de obter um edifício e, assim, a $1^{\circ}$ de março de 1828 abre-se o curso jurídico no já velho Convento de São Francisco. Resistindo ao tempo, o velho Convento somente em 1936 foi substituido pelo atual prédio, cuja arquitetura neocolonial foi projetada por Ricardo Severo, do Escritório de Arquitetura Ramos de Azevedo que pela sobriedade de suas linhas e pela tradição histórica que sustenta, é ponto convergente de respeito, consideração e ufania de todos os paulistanos e paulistas.

São Paulo, outubro de 1999. 


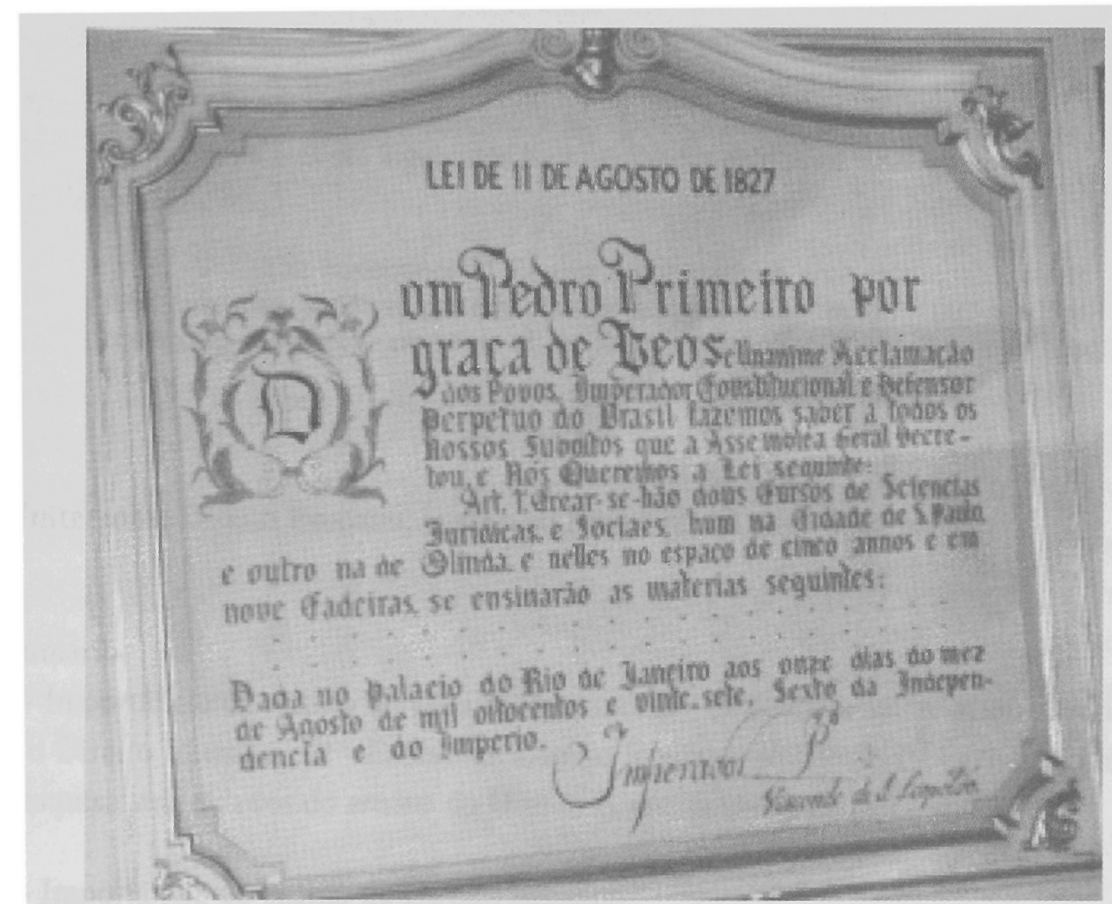

Reprodução da Lei de 11 de agosto de 1827 que criou os cursos juridicos no Brasil. Extrida da Sala da Congregação da Faculdade de Direito da USP 